\title{
MISCELLANEA
}

\section{Pulmonary Aspergillosis}

\author{
From the Medical Department, Ministry of Pensions \\ and National Insurance
}

(RECEIVED FOR PUBLICATION APRIL 27, 1964)

Pulmonary aspergillosis is a disease caused by fungal infection of the lungs. The pathogenic member of the species is usually Aspergillus fumigatus although exceptionally other species may be responsible for the disease. This fungus proliferates on decaying organic matter and the spores have a world-wide distribution in both rural and urban air.

The fungus is a common pathogen of birds, both wild and in captivity, but in the vast majority of instances inhalation of spores by man causes no disability. If the exposure is excessive a temporary inflammation of the main lung airways may develop but this leaves no aftereffects. There are, however, three types of infection which may occur in man.

\section{Types of Infection}

Saprophytic.-The fungus may proliferate in a previously damaged lung. Among lung diseases complicated by such a secondary invasion are malignant disease, tuberculosis, lung abscess, unresolved pneumonia, and pneumoconiosis. To what extent the fungus infection worsens the condition of the patient is uncertain, but it probably contains a toxin which increases the destruction of lung tissue, and plugs of the fungus may block the airways.

Allergic.-In rare instances inhalation of the fungal spores gives rise to episodes of asthma and fever accompanied by areas of pulmonary consolidation and collapse. Sufferers may in fact be chronic asthmatics who, on exposure to the fungal spores, develop influenza-like episodes with aggravation of their asthma.

The attacks usually resolve within a few days but exceptionally they may go on for months. In these chronic cases, an interstitial pulmonary fibrosis may result. The sputum contains tenacious plugs incorporating filaments of fungus and eosinophillic granular leucocytes. There is also an abnormal number of eosinophilic cells circulating in the blood.

Disseminating.-In rare instances during the terminal phases of certain systemic diseases a dissemination of the fungus infection may occur. This is probably due to the lowering of resistance by the underlying disease and may also be assisted by the drugs being administered, particularly the steroids and antibiotics.
Discussion

Of the types of the disease described above, the first or the third could not be regarded as of occupational origin, although one or other might exceptionally be accepted as a sequela of a prescribed disease; it could however be argued that the second type might arise through occupational factors, and it is this allergic aspergillosis with which the remainder of this note is concerned.

Diagnosis.-The syndrome of asthma, eosinophilia, pulmonary infiltration, and excess of eosinophils in the blood is not confined to those who have inhaled aspergillus spores. Pulmonary eosinophilia may develop as a result of exposure to a wide range of antigens, sometimes traceable to proteins contained in certain foods. In other instances, infestation with protozoa has been shown to cause transient lung infiltration with eosinophils. In the majority of cases, however, especially in temperate climates, no cause can be demonstrated.

A particular difficulty in diagnosis arises from the fact that a large percentage of the cases of chronic asthma due to an allergic response to antigens other than those of $A$. fumigatus also show an allergic response to this fungus. Precipitins are found in the serum of about $5 \%$ of these cases, and an immediate skin reaction is common. However, trial inhalation tests with aspergillus extracts are negative.

Despite these difficulties, the diagnosis of allergic pulmonary aspergillosis should be possible with reasonable certainty given the necessary facilities. Skin tests are usually positive with an immediate weal reaction followed by a nodule in the skin which, on biopsy, shows a cellular eosinophilic reaction. Serum precipitin reactions are usually positive and trial inhalation tests with aspergillus extracts give a positive result.

Pulmonary function tests are of little value in the diagnosis of any type of aspergillosis except perhaps in demonstrating an interstitial fibrosis on the rare occasions that it occurs as a late sequela of the allergic type of the disease.

Incidence.-The incidence of the disease is unknown, and it may well be that many cases are never correctly diagnosed. The available evidence indicates that it is a rare condition which only occasionally gives rise to more than a transient disability. It is perhaps reasonable to suppose that those exposed to the dust of decayed vegetable matter would run a higher risk of contracting the disease than the general population. Against this supposition is the fact that the spores of $A$. fumigatus are to be found everywhere, and there is no evidence to show that the condition is in fact significantly more 
common in any particular group of occupations. A probably identical condition has been described on the Continent as occurring in pigeon fanciers, who use grain held in their mouths to force-feed the young birds, the so-called pigeon crammers' disease.

Cause.-As indicated, $A$. fumigatus is normally nonpathogenic and it is not known why an allergic response should occur in a minority of individuals exposed to it. Presumably, however, this is a further example of an abnormal and genetically determined reaction to a foreign protein.

\section{An Early Sign of Lead Poisoning}

\section{BY}

\section{W. G. PEARCE and W. A. REYNARD}

From the Oxford Eye Hospital and Medical Department, Pressed Steel Co. Ltd., Oxford

(RECEIVED FOR PUBLICATION JANUARY 29, 1964)

In the New England Journal of Medicine of October 10, 1963 an article by N. Sonkin described Retinal Stippling - a New Physical Sign in the Early Diagnosis of Lead Poisoning. In this paper Sonkin described stippling around the optic disc which consisted of glistening grey discrete spots that he considered to be lead pigment. This was noted to be present in eight men who had been mixing various lead compounds for the manufacture of wire insulation. These deposits were present in all of the men even though the urinary lead values in some of the men were not significant. Four months after removal from exposure to the lead compounds this physical sign had disappeared. Sonkin considered that this sign may be present before there is laboratory evidence of lead toxicity.

In many industrial processes involving a lead hazard, the industrial medical officer has need of every possible sign that might assist him in drawing that most difficult line which separates lead absorption from lead intoxication. All men on a lead process absorb small quantities of lead: what is needed is a reliable sign which will indicate excessive absorption or early lead poisoning and therefore the need to remove the worker from the environment containing lead.

It was therefore felt that this new retinal sign should be investigated in a group of workmen known to be exposed to lead and, in varying degree, to be absorbing lead.

In a factory manufacturing motor car bodies, approximately 800 men are working in an atmosphere containing finely divided (some less than 5 microns) solder dust. Every two months they receive a clinical examination, haemoglobin estimation, enumeration of punctate basophilia of the erythrocytes, and a qualitative examination of the urine for coproporphyrin. Each day a batch of men is examined, and these are selected at random from all parts of the factory according only to the dictates of sustained production.

It was decided to examine the fundus of each man presenting in the daily batches until 100 had been examined, the other tests being continued collaterally. In fact 102 men had their fundi examined by an ophthalmologist using a Keeler Specialist Ophthalmoscope in a dark room.

Of the 102 men examined, 11 showed evidence of lead absorption to a degree that caused them to be removed from the process. The findings in these men are shown in the Table.

TABLE

\begin{tabular}{|c|c|c|c|}
\hline Haemoglobin ( $\%)$ & $\begin{array}{c}\text { Qualitative } \\
\text { Coproporphyrin* }\end{array}$ & $\begin{array}{c}\text { Punctates } \\
\text { Per Million } \\
\text { R.B.C.† }\end{array}$ & $\begin{array}{l}\text { Period on } \\
\text { Lead } \\
\text { Work }\end{array}$ \\
\hline $\begin{array}{r}103 \\
119 \\
100 \\
106 \\
89 \\
103 \\
93 \\
108 \\
96 \\
109 \\
101\end{array}$ & $\begin{array}{l}++++ \\
++++ \\
++++ \\
++++ \\
++++ \\
++++ \\
++++ \\
++++ \\
++++ \\
++++ \\
++++\end{array}$ & $\begin{array}{r}2,100 \\
6,800 \\
2,700 \\
7,300 \\
4,200 \\
6,300 \\
3,000 \\
4,500 \\
4,700 \\
2,700 \\
11,800\end{array}$ & $\begin{array}{r}15 \mathrm{yr} 9 \mathrm{mth} \\
3 \mathrm{yr} 7 \mathrm{mth} \\
3 \mathrm{yr} 5 \mathrm{mth} \\
9 \mathrm{yr} 4 \mathrm{mth} \\
16 \mathrm{yr} 6 \mathrm{mth} \\
13 \mathrm{yr} 3 \mathrm{mth} \\
2 \mathrm{yr} \\
9 \mathrm{yr} \\
15 \mathrm{yr} \\
17 \mathrm{yr} 7 \mathrm{mth} \\
5 \mathrm{yr}\end{array}$ \\
\hline $\begin{array}{r}++ \\
+++ \\
++++\end{array}$ & , & $\begin{array}{l}0 \mu \mathrm{g} . / \mathrm{day} \\
00 \mu \mathrm{g} / \mathrm{day} \\
0-1,500 \mu \mathrm{g} . / \mathrm{d} \\
0-3,000 \mu \mathrm{g} . / \mathrm{d}\end{array}$ & $y$ \\
\hline
\end{tabular}

Not one of the 102 men examined, including the 11 with signs of excessive lead absorption, showed the discrete grey deposits around the optic disc described by Sonkin.

Having failed to find retinal stippling in men known to be absorbing lead to a degree which tests at present in use cause us to grade as excessive, we cannot recommend that examination of the fundus has any place in the medical control of workmen exposed to lead absorption. 